\title{
Safety Knowledge of LPG Auto Drivers and LPG Tank Drivers
}

\author{
Gargi Bhattacharjee $^{1}$, Susmita Neogi ${ }^{1}$, Sudip Kumar Das ${ }^{2}$ \\ ${ }^{1}$ Home Science Department, University of Calcutta, Kolkata, India \\ ${ }^{2}$ Chemical Engineering Department, University of Calcutta, Kolkata, India \\ E-mail: drsudipkdas@vsnl.net \\ Received July 30, 2011; revised November 8, 2011; accepted November 20, 2011
}

\begin{abstract}
The paper deals with the survey about the knowledge of safety during their occupational time in the LPG auto drivers and tank drivers. A structured questionnaires was developed and used for interview on LPG auto ( $\mathrm{N}=150)$ and LPG tanker $(\mathrm{N}=150)$ drivers. Statistical results show that there is a significant difference on auto driver's safety knowledge without training and tanker driver's knowledge with training at regular interval of time.
\end{abstract}

Keywords: Auto LPG, Safety Knowledge, Training, Drivers

\section{Introduction}

In the mid to late 90's, air pollution has become an issue attracting wide public concern. To alleviate the air pollution problem, one of the measures identified was to replace diesel vehicles with vehicles using cleaner fuel, i.e., Liquefied Petroleum Gas (LPG), which is a readily available fuel. In an order on July 18, 2008 a Division Bench of the Calcutta High Court has ordered that only four-stroke auto rickshaws running on Liquefied Petroleum Gas (LPG) will be allowed to ply on Kolkata's roads and also order banning all commercial vehicles older than 15 years. The Bench comprising Chief Justice S. S. Nijjar and Justice P. C. Ghosh observed that there would be no conversion of two-stroke auto-rickshaws. They will have to be replaced by new four-stroke autos with LPG engines [1].

Auto LPG or Liquefied Petroleum Gas is a generic name for mixtures of hydrocarbons (mainly propane and butane) which exists as vapor under ambient conditions and can be changed into liquid state by applying moderate pressures [2]. Auto LPG is a gas at atmospheric pressure and normal temperatures, but it can be liquefied when moderate pressure is applied or when the temperature is sufficiently reduced. This property makes the fuel an ideal energy source for a wide range of applications, as it can be easily condensed, packaged, stored and utilized. When the pressure is released, the liquid makes up about 250 times its volume as gas, so large amounts of energy can be stored and transported compactly [3].
Safety knowledge or safety education means improveing knowledge, skill, attitude and morale of the workers. It means it is a process of systematic instructions and development of character or mental powers of the workers. It must prevent both unsafe conditions in the working areas as well as unsafe acts committed by the workers. Safety training alone is the remedy for correcting unsafe acts of the workers. Safety education is vital and essential for all accident prevention work in industries. It is generally true by the evidences that well-trained and careful men may avoid injury on dangerous work than that of the untrained and careless man may be injured under the same condition [4]. The safety educated person is more likely to regard an accident as being predictable, preventable, and non-accidental. Hence safety education plays an important role in the preventive measures. As knowledge increases, one's behaviour becomes more intentional, so that unanticipated events are less likely to occur. The role of safety education is to increase knowledge, thereby decreasing the proportion of unintended behaviour and increasing the level of anticipation, and the possibility of avoiding danger [5]. Safety training is one of the solutions to perform safe work practices and a tool for motivating the employees to change [6].

\section{The Present Study}

The present study is conducted to measure safety knowledge of the auto LPG users. Survey method was con- 
ducted through questionnaire and then the responds are statistically analysed. The objectives of the study are:

1) To determine safety knowledge among LPG auto drivers and LPG tanker drivers;

2) To find out how safety training increases safety knowledge of auto LPG users;

3) Creating a general awareness of health and safety issue on LPG among auto and tanker drivers;

4) To investigate what is the real situation of safety knowledge among LPG auto and tanker drivers and the personal attributes of participants like age, educational qualification, and monthly income.

To fulfil the objectives the Null hypotheses was used for both cases, i.e.,

1) Safety knowledge of auto drivers on LPG is positively high without training;

2) Safety knowledge of tanker drivers on LPG positively low with training.

\section{Methods}

\subsection{Participant and Procedures}

This study surveyed on LPG auto drivers and tanker drivers in an around Kolkata and Haldia. The sample size of auto drivers $(\mathrm{N}=150)$, tanker drivers $(\mathrm{N}=150)$ and total was 300. Statistical analysis conducted on the basis of the responses of the questionnaire as shown in Appendix 1 and 2 for auto drivers and tanker drivers respectively. Initially questionnaires have been prepared, then experts from M/S Petroleum and Explosive Safety Organisation, East Circle, Govt. of India, have corrected the questionnaires and used for survey.

\subsection{Sample 1}

Data of auto drivers were collected from various LPG filling stations at Mniktala, Kankurgachi, Sealdah, Sintheemore and Silpara in Kolkata, West Bengal, India. With the help of the filling station manager and explaining the aim of the study, the questionnaires were distributed to the LPG auto drivers and they were requested to fill up the questionnaire.

\subsection{Sample 2}

The questionnaires were distributed to the tanker drivers at the M/S IOC Petronas Limited, Haldia, who came to fill up their tankers. The major route of these tankers are Haldia to Patna, Raninagar; Kalyani; Paharpur; Durgapur; Kolaghat; Budge Budge; different parts of Orissa, Assam and Jharkhand; Baksara, Banaras, Hazimbag, Jamshedpur, , Siliguri, Balasore and Kolkata. After explaining the aim of the study they were asked to fill up the question- naire. Structured questionnaire was used in the assessment. The participants' responded to the questionnaire during their free time. It was presented in English language and where respondents with poor literacy skills had problem understanding the language, there was an interpreter is explained in their local language.

\subsection{Scoring}

After collecting the data from the sample the responses of each subject were scored. In this investigation the questionnaire of LPG auto drivers consisted of 20 questions and for LPG tanker drivers consisted 25 questions, each had two options, "YES", and "NO". Score of 2 was given for "YES" responses; score of 1 was given for "NO". After scoring each question the total score was computed for each individual subject by scoring up the item score. Then the scores were tabulated for statistical analysis. The two questionnaires have different number of items, so the total score will vary for the two groups of sample. Subsequently mean will vary because of differrence in total scores.

\subsection{Statistical Analysis}

After scoring the responses and computing the total score for each individual the mean and standard deviation (SD) were calculated of these scores were computed for LPG auto drivers and LPG tanker drivers separately. Then the difference between the means was computed and the $t$ value for the independent samples of equal sizes was calculated to see the level of significance.

\subsection{Reliability}

Reliability is the consistency or repeatability of the measures as collected from the questionnaires for auto and tanker driver respectively. In this survey the internal consistency method is used. The internal scale reliability (Cronbach Alpha) of the questionnaire for LPG auto driver estimated as 0.47 which is below the acceptable limit where as for the LPG tanker drivers it was 0.65 which is above acceptable limit of 0.6 [7]. So, it was decided to keep the questionnaire further in validation in case of auto driver. The $\mathrm{F}$ ratio of the scores of questionnaire for auto driver was 4.00 which were significant at $p<0.05$ level. Hence, it was decided that the questionnaire for auto driver is also valid for this study.

\section{Results and Discussion}

\subsection{Auto Driver}

After statistical analysis it is shown that in case of auto 
drivers mean score of "YES" and "NO" are 10.45 and 14.77 respectively. The calculated $t$ value is 10.843 which is greater than the table value at $p<0.05$ level [8]. So, the first null hypothesis is rejected and alternative hypothesis is accepted. The knowledge of LPG auto drivers on safety is low, because they did not get any safety training from any authorities. So, their mean score of "NO" is greater than the mean score of "YES" and for these reasons the LPG auto drivers are known little about safety aspects on LPG. Beside this the other general information are also important for the measurement of safety perceptions likes age, income, educational qualification which are also related to occupational satisfaction, accidental risks, emergency responses. Table 1 shows age range of auto drivers. Most of auto drivers' fall on the age range between 26 - 35 yrs. and maximum age of auto driver is 73 yrs. Table 2 shows income range of LPG auto drivers. The maximum income range of LPG auto drivers is Rupees 5001 - 6000 per month and highest income is Rupees 15,000 per month. Table 3 shows educational qualifications. The sample was categorized into four educational groups based on their responses, basic education, secondary education, higher secondary, graduation level. Most of the auto drivers educational qualification is secondary level (Class V-X). Table 4 represents the percentage score on safety knowledge of LPG auto drivers. This table shows that only $3 \%$ drivers acquired $91 \%$ - 100\% which is high range of per-

Table 1. Age range of LPG auto drivers.

\begin{tabular}{cc}
\hline Age range & No \\
\hline $15-25$ & 16 \\
$26-35$ & 73 \\
$36-45$ & 40 \\
$46-55$ & 9 \\
$56-65$ & 0 \\
73 & 1 \\
\hline
\end{tabular}

Table 2. Income range of LPG auto drivers.

\begin{tabular}{cc}
\hline Income range & No \\
\hline $1000-2000$ & 1 \\
$2001-3000$ & 11 \\
$3001-4000$ & 10 \\
$4001-5000$ & 13 \\
$5001-6000$ & 40 \\
$6001-7000$ & 3 \\
$7001-8000$ & 12 \\
$8001-9000$ & 10 \\
$9001-10,000$ & 2 \\
12,000 & 7 \\
15,000 & 1 \\
\hline
\end{tabular}

Table 3. Educational qualifications of LPG auto drivers.

\begin{tabular}{ccccc}
\hline Sample & $\begin{array}{c}\text { Basic } \\
\text { (Class I-IV) }\end{array}$ & $\begin{array}{c}\text { Secondary } \\
\text { (Class V-X) }\end{array}$ & $\begin{array}{c}\text { Higher secondary } \\
\text { (Class XI-XII) }\end{array}$ & Graduation \\
\hline $\begin{array}{c}\text { Auto } \\
\text { driver }\end{array}$ & 16 & 105 & 13 & 6 \\
Mean & 0.10 & 1.4 & 0.26 & 0.16 \\
\hline
\end{tabular}

Table 4. Percentage scores on safety knowledge of LPG auto drivers.

\begin{tabular}{cc}
\hline Range of scores & Percentage of scores \\
\hline $10-20$ & 17 \\
$21-30$ & 22 \\
$31-40$ & 22 \\
$41-50$ & 22 \\
$51-60$ & 25 \\
$61-70$ & 16 \\
$71-80$ & 13 \\
$81-90$ & 10 \\
$91-100$ & 3 \\
\hline
\end{tabular}

centage scores and 17\% drivers acquired 10\% - 20\% achievement of safety knowledge which is low range of percentage scores on LPG auto driver. The majority of scores of the LPG auto drivers falls on between 51\% $60 \%$.

\subsection{Tanker Driver}

After statistical analysis it is shown that in case of tanker drivers mean score of "YES" and "NO" are respectively 41.16 and 4.42. The calculated $t$ value is 96.48 which is greater than the table value at $p<0.05$ level [8]. So, the second null hypothesis is rejected and alternative hypothesis is accepted. The knowledge of LPG tanker drivers on safety is high, because they get safety training from various authorities at regular interval of time, i.e., yearly once or twice. So, their mean score of "YES" is greater than the mean score of "NO" and for these reasons the LPG tanker drivers knowledge are high about safety aspects of LPG. Table 5 shows age range of tanker drivers. Most of tanker drivers fall on the age range between 26 - 35 yrs. and maximum age of tanker driver in between 56 - 65. Table 6 shows income range. Tanker drivers' maximum income range is rupees 1000 - 2000 per month and highest income is Rupees 7000 per month. Table 7 indicates that most of tanker drivers educational level is secondary level (Class V-X). Table 8 represents the percentage scores on safety knowledge of LPG tanker drivers. This table shows that $19 \%$ tanker drivers acquired $91 \%$ - 100\% which is high range of percentage scores and $1 \%$ tanker drivers acquired 40\% - 50\% achi- 
Table 5. Age range of LPG tanker drivers.

\begin{tabular}{cc}
\hline Age range & No. \\
\hline $15-25$ & 33 \\
$26-35$ & 74 \\
$36-45$ & 31 \\
$46-55$ & 8 \\
$56-65$ & 1 \\
\hline
\end{tabular}

Table 6. Income range of LPG tanker drivers.

\begin{tabular}{cc}
\hline Income range & No. \\
\hline $1000-2000$ & 59 \\
$2001-3000$ & 40 \\
$3001-4000$ & 9 \\
$4001-5000$ & 3 \\
$5001-6000$ & 2 \\
$6001-7000$ & 1 \\
\hline
\end{tabular}

Table 7. Educational qualifications of LPG tanker drivers.

\begin{tabular}{ccccc}
\hline Sample & $\begin{array}{c}\text { Basic } \\
\text { (Class I-IV) }\end{array}$ & $\begin{array}{c}\text { Secondary } \\
\text { (Class V-X) }\end{array}$ & $\begin{array}{c}\text { Higher secondary } \\
\text { (Class XI-XII) }\end{array}$ & Graduation \\
\hline $\begin{array}{c}\text { Tanker } \\
\text { driver }\end{array}$ & 10 & 111 & 14 & 1 \\
Mean & 0.06 & 1.48 & 0.28 & 0.02 \\
\hline
\end{tabular}

Table 8. Percentage scores on safety knowledge of LPG tanker drivers.

\begin{tabular}{cc}
\hline Range of scores & Percentage of scores \\
\hline $40-50$ & 1 \\
$51-60$ & 5 \\
$61-70$ & 9 \\
$71-80$ & 32 \\
$81-90$ & 84 \\
$91-100$ & 19 \\
\hline
\end{tabular}

evement of safety knowledge which is low range of percentage scores on LPG. The majority of scores of the LPG tanker drivers falls on between $81 \%$ - 90\%.

During the survey many auto drivers told about the safety problems on their job. They are not trained, so they are worried about in emergency situation. But tanker drivers are well trained, so they know the primary emergency preparedness. For auto driver they informed and gain some knowledge about the general awareness, health and safety issues on LPG. The real situation is large quantities of auto LPG use in vehicle at present in West Bengal particularly in and around Kolkata. The Government of West Bengal forced recently that all auto should run by LPG by the law of court but neither the LPG supplier of the Govt. itself arrange any training programme for auto drivers. So, their safety knowledge is very poor. They had no idea about what to do in emergency situation.

\section{Recommendations}

Some general recommendations on auto LPG operations,

1) Safety should be the prominent place in the training of anyone who works with LPG. So, first and most important safety equipment is workers knowledge also to know the physical and chemical properties of LPG.

2) All LPG operations must be carried out by personnel well trained in LPG operations.

3) Engage only trained and competent workers in LPG filling station and filling vehicle related jobs.

4) When working on road sides, ensure safe places for parking and working on vehicles, e.g., away from drains, pits and other openings in the ground and all sources of ignition.

5) Safety equipment like personal protective equipment, safety cloths, goggles etc. to be always use in working place to avoid any damage.

6) Gas detectors to be provided at different locations of the LPG filling stations. Whenever leak is detected then the system gives an audible alarm.

7) Avoid the roadside check for leaks and other damages to the LPG system on the auto rickshaw or tankers.

8) If leak detected do not panic, stop the vehicles and starts emergency plan, inform local police station, fire station, emergency medical facilities, public awareness system, warning people away from the area and also switch off electricity and all ignition sources.

9) Provides the operators suitable first aid kit.

10) Phone numbers of the local fire department, emergency medical facility, and other appropriate public safety agencies to be available to the drivers. Note book containing these emergency numbers to be carried out by the drivers.

11) Smoking to be avoided as it may produce flame or sparks which may create an accidental situation.

12) Never leave vehicle unattended while in operation or when set up for operation.

13) Drivers to be advice do not wear clothing made of synthetic fibres or any other material that tends to produce static electricity.

14) Drivers to be advice to carry out mock drill at least once in a year to review and practice emergency procedures.

15) Periodical training for the drivers to be provided by the oil companies or the Government and also provides them certificates.

\section{Conclusions}

A structured questionnaire was developed and used for interview on LPG auto and LPG tanker drivers to know the knowledge of safety and emergency preparedness. Statistical results show that there is a significant differ- 
rence on auto drivers' safety knowledge as they were not received any training and tanker drivers' knowledge with training at regular interval of time. A list of recommendations is incorporated for used to train both types of drivers.

\section{Acknowledgements}

Authors are very thankful to Mr.Amalesh Dutta, Indian Oil Petronas Pvt. Ltd., Haldia for his kind help in survey process. Authors are also thankful to Rahul Ghosh, Sreedip Ghose, Pinaki Naskar, Girija Sankar Mundra students of B.Tech Chemical Engineering, University of Calcutta for participating to complete the survey.

\section{References}

[1] The Hindu News, 2011. http://beta.thehindu.com/news/states/other-states/article1

\section{Nomenclature}

F: Compare the variance of the two independent samples;

$p$ : In rejection region, this is the area in the tail beyond 0826.ece

[2] AUTO-LPG, 2011. http://www.piponlinesite.com/Safety_Tips_on_Auto_LP G.PDF

[3] Auto Gas: Gas Stations, 2011. http://www.iocl.com/Products/AutoGas.aspx

[4] H. W. Heinrich, "Industrial Accident Prevention; A Scientific Approach,” 4th Edition, Mc-Graw Hill Book Company Inc., New York, 1959.

[5] A. E. Florio and G. T. Stafford, "Safety Education," 4th Edition, Mc Graw-Hill Book Company, New York, 1979.

[6] P. S. Ray and P. A. Bishop, "Can Training Alone Ensure a Safe Workplace?” Professional Safety, 1995, pp. 56-59.

[7] J. F. Hair, R. E. Anderson, R. L. Tatham and W. C. Black, "Multivariate Data Analysis with Readings," $4^{\text {th }}$ Edition, Prentice-Hall, Upper Saddle River, 1995.

[8] V. Volk, “Applied Statistics for Engineers,” McGrawHill Book Company, New York, 1958.

observed value of the test statistics

$\mathrm{N}$ : Sample size;

SD: Standard deviation;

$t$ : Judging the significance of the mean of difference between the two related samples. 


\section{Appendix 1. Self-constructed questionnaire for LPG auto drivers. \\ SAFETY INVESTIGATION QUESTIONNAIRE \\ General information}

Name-

Age-

Educational Qualification-

Location-

Time-

Date-

Monthly / Daily income-

\begin{tabular}{|c|c|c|}
\hline Sl. No & QUESTIONS & YES/NO \\
\hline 1 & Do you know the full form of LPG? & \\
\hline 2 & Do you know why we use auto LPG? & \\
\hline 3 & Is there adequate supply of auto LPG? & \\
\hline 4 & Do you know any risks of health for using LPG? & \\
\hline 5 & Do you know the safety operations of auto LPG? & \\
\hline 6 & Did you receive any training before running auto LPG? & \\
\hline 7 & Do you know how refill the empty container? & \\
\hline 8 & Did you receive any training for handling any emergencies? & \\
\hline 9 & Does training include hands on experience? & \\
\hline 10 & Do you know how to diagnose the leakage or any failure of LPG? & \\
\hline 11 & Is there any technical support available during emergencies? & \\
\hline 12 & Can operators confidentially report problems, errors? & \\
\hline 13 & Is information used and acted upon to minimize risks? & \\
\hline 14 & Are there sufficient communication resources and personnel to handle communications during emergencies? & \\
\hline 15 & Do you know any sign of leakage? & \\
\hline 16 & Do you know the procedure to remove the leak cylinder? & \\
\hline 17 & Do you know the right procedure of maintain the containers? & \\
\hline 18 & Is station operators and there staff are well trained about the safe use of auto LPG? & \\
\hline 19 & Do you own the vehicle? & \\
\hline 20 & Are you satisfied with Auto LPG? & \\
\hline
\end{tabular}




\section{Appendix 2. Self-constructed questionnaire for LPG tanker drivers. \\ SAFETY INVESTIGATION QUESTIONNAIRE \\ General information}

Name-

Age-

Educational Qualification-

Location-

Tank registration no.-

Monthly/Daily income-

Time-

Date-

\begin{tabular}{|c|c|c|}
\hline Sl. No. & QUESTIONS & YES/NO \\
\hline 1 & Do you know the full form of LPG? & \\
\hline 2 & Do you know why we use auto LPG? & \\
\hline 3 & Is there adequate supply of auto LPG? & \\
\hline 4 & Do you know any risks of health for using LPG? & \\
\hline 5 & Are you using any personal protective equipment? & \\
\hline 6 & Do you know the safety operations of auto LPG? & \\
\hline 7 & Are you trained on about hazardous nature of LPG? & \\
\hline 8 & Do you know the procedure of refill/delivery of the tank? & \\
\hline 9 & Did you receive any training for handling any emergencies? & \\
\hline 10 & Does training include hands on experience? & \\
\hline 11 & Whether training programme organized periodically? & \\
\hline 12 & Any instruction booklets/operating manuals provided in local languages? & \\
\hline 13 & Whether important Do's and Don'ts displayed prominently? & \\
\hline 14 & 'No Smoking' and other caution sing in local language displayed at prominent places? & \\
\hline 15 & Do you know how to diagnose the leakage or any failure of LPG? & \\
\hline 16 & Whether gas detector system has been provided in the vehicle? & \\
\hline 17 & Whether inspection/visual checks are done to detect leaky/defective cylinders? & \\
\hline 18 & Whether cylinder repairs/valve change etc. are supervised? & \\
\hline 19 & Is there any technical support available during emergencies? & \\
\hline 20 & Whether important telephone no./emergency service center provided for emergency communication? & \\
\hline 21 & Can operators confidentially report problems, errors? & \\
\hline 22 & Do you know the right procedure of maintain the cylinders? & \\
\hline 23 & Is station operators and there staff are well trained about the safe use and handle of auto LPG? & \\
\hline 24 & Whether explosimeter checks are done before releasing the truck? & \\
\hline 25 & Do you own the vehicle? & \\
\hline
\end{tabular}

